\title{
Haemodynamic changes during high frequency oscillation for respiratory distress syndrome
}

\author{
B Laubscher, G van Melle, C-L Fawer, N Sekarski, A Calame
}

\begin{abstract}
In a crossover trial left ventricular output (LVO), cerebral blood flow velocity (CBFV), and resistance index (RI) of the anterior cerebral artery were compared using Doppler ultrasonography, in eight preterm infants with respiratory distress syndrome (RDS) during conventional mechanical ventilation and high frequency oscillation. LVO was $14 \%$ to $18 \%$ lower with high frequency oscillation. There were no significant changes in CBFV. On the first day of life there was a trend towards lower RI on high frequency oscillation; the fall in LVO on high frequency oscillation was not related to lung hyperinflation.
\end{abstract}

Changes in ventilation type (from conventional mechanical ventilation to high frequency oscillation, or vice versa) can induce significant LVO changes in preterm infants with RDS.

(Arch Dis Child 1996; 74: F172-F176)

Keywords: high frequency oscillation, cardiac output, cerebral blood flow, Doppler ultrasonography.

High frequency oscillation is an effective way of supporting gas exchange in critically ill neonates with respiratory distress syndrome (RDS). ${ }^{2}$ Cerebral damage during high frequency oscillation is a controversial issue. While Clarke et $a l^{1}$ and Ogawa et $a l^{2}$ reported no increased risk of intracranial haemorrhage, both $\mathrm{HIFI}^{3}$ and $\mathrm{HIFO}^{4}$ trials showed that severe intracranial haemorrhage was more common during high frequency oscillation than during conventional mechanical ventilation. In premature baboons with $\mathrm{RDS}^{5}$ or in surfactant deficient adult rabbits, ${ }^{6}$ high frequency oscillation did not affect the cerebral blood flow. Animal studies of cardiac output during high frequency oscillation showed that increasing mean airway pressure (Paw) could decrease cardiac output, ${ }^{7}$ but that strategies which avoid lung hyperinflation prevented a fall. ${ }^{56}$

To our knowledge, no study on cardiac output or on left ventricular output (LVO) and cerebral blood flow velocity (CBFV) has been reported in preterm infants with RDS during high frequency oscillation. Based on animal studies, ${ }^{56}$ our hypothesis was that high frequency oscillation, used with a cautious strategy of lung volume recruitment, would not impair $\mathrm{LVO}$ or CBFV in premature infants with RDS.

\section{Methods}

Ten preterm infants with a clinical and radiological diagnosis of RDS were studied. None had presented with significant perinatal asphyxia (defined as an Apgar score $<4$ at 5 minutes and a cord blood $\mathrm{pH}<7 \cdot 10$ ), and none had a congenital heart or brain malformation or an intracerebral haemorrhage at the time of the study. Their median birthweight was $1395 \mathrm{~g}$ (range 650-2650 g) and their gestational age 31 weeks (26-36 weeks). Parental informed consent was obtained in all cases and the protocol was approved by the research ethics committee of the Centre Hospitalier Universitaire Vaudois.

The study comprised two phases. Initially, all infants were on a time-cycled, pressurelimited ventilator (Bear Cub BP 2001) with a positive end expiratory pressure (PEEP) of 4-6 $\mathrm{cm} \mathrm{H} \mathrm{H}_{2} \mathrm{O}$ and an inspiratory time of $0 \cdot 4-0 \cdot 7$ seconds. $\mathrm{FIO}_{2}$, peak inspiratory pressure, and breath rate were set to maintain $\mathrm{PaO}_{2}$ between 60 and $80 \mathrm{~mm} \mathrm{Hg}\left(8\right.$ and $10.7 \mathrm{kPa}$ ) and $\mathrm{PaCO}_{2}$ between 40 and $50 \mathrm{~mm} \mathrm{Hg}(5.3$ and $6.7 \mathrm{kPa})$. All infants received continuous morphine infusion and were paralysed with pancuronium bromide. After initial resuscitation and stabilisation of blood pressure with intravenous albumin $20 \%$ (median $24 \mathrm{ml} / \mathrm{kg}$ (range 4-35)) or dobutamine infusion (two infants), a chest radiograph was taken. The endotracheal tube was suctioned and $5 \mathrm{ml} / \mathrm{kg}$ of synthetic surfactant (Exosurf) was instilled over 20 minutes via the sideport on the special endotracheal tube adaptor, without interrupting mechanical ventilation. Five minutes after the end of surfactant administration, ventilation settings, mean arterial blood pressure (MABP), arterial gases, CBFV and LVO were measured. The infants were then immediately transferred to high frequency oscillation. Five 1 second sustained inflations at $10 \mathrm{~cm} \mathrm{H}_{2} \mathrm{O}$ over the Paw delivered by conventional mechanical ventilation were administered. After five minutes, the same variables were measured. These paired measurements constituted phase 1 of the study (T1).

High frequency oscillation was obtained using an OHF-1 high frequency oscillatory ventilator (Dufour Cie, Villeneuve d'Asq, France) which generates sinusoidal pressure swings with a motor driven piston at an inspiratory:expiratory ratio of $1: 1$. The frequency was set at $15 \mathrm{~Hz}$. Oscillatory amplitude was adjusted to achieve adequate $\mathrm{PaCO}_{2}$. The initial Paw on high frequency oscillation was $2 \mathrm{~cm} \mathrm{H}_{2} \mathrm{O}$ higher than that delivered by conventional mechanical ventilation. $A$ chest radiograph was obtained a few hours later with the same Paw and lung inflation was assessed. Hyperinflation was defined as flattening of the diaphragm borders below the eighth posterior thoracic rib. 
$\mathrm{AaDO}_{2}$ was computed according to the following formula:

$$
713 \cdot \mathrm{FIO}_{2}-\mathrm{PaCO}_{2}-\mathrm{PaO}_{2}(\mathrm{mmHg}) \text {. }
$$

During recovery from RDS, infants were transferred from high frequency oscillation to conventional mechanical ventilation. Ventilator settings on conventional mechanical ventilation were as described initially. At this stage, all infants were receiving continuous morphine and dobutamine infusion. Three out of eight infants were paralysed with pancuronium MABP. Ventilation settings, bromide, arterial gases, CBFV and LVO were again measured during high frequency oscillation and conventional mechanical ventilation. These paired measurements constituted phase 2 of the study (T2).

HAEMODYNAMIC MEASUREMENT TECHNIQUES Doppler ultrasound recordings were made using the duplex Doppler Acuson 128 with a 7.0 $\mathrm{MHz}$ transducer. All infants were kept supine with the head in anatomical position during measurements. Each variable was analysed on line, but the recorded values were read on photographic prints only after the second set of measurements. All measurements were performed by one author (BL).

The anterior cerebral artery was insonated anterior to the corpus callosum in parasagittal section through the anterior fontanelle. Optimal Doppler signal was obtained by simultaneously listening to the audio signal and observing the sonogram in real time. The CBFV were measured at an angle as close to zero as possible. Pourcelot's resistance index $(R I=(S-D) / S)$ was calculated as the mean of five waveforms, where $S$ and $D$ are the maximum and the minimum blood flow velocities during one cardiac cycle.

LVO was calculated according to the following formula:

$\mathrm{LVO}=$ aortic flow velocity integral $\cdot$ aortic root area $\cdot$ heart rate/birth weight $(\mathrm{ml} / \mathrm{min} / \mathrm{kg})^{8}$

Aortic flow velocity curve was recorded from the suprasternal window using continuous wave Doppler. The beam was aligned in the ascending aorta. Maximal Doppler signal was obtained by simultaneously listening and observing the signal. The aortic flow velocity was integrated by tracing the area of the Doppler curve. Aortic flow velocity integral was averaged over five consecutive beats. The aortic root diameter was recorded from the parasternal long axis window at the level of the bases of the aortic leaflets in early or mid systole, from inner edge to inner edge. The diameter was averaged over five consecutive measurements. The aortic root area was calculated as: $\pi(0.5 \text { diameter })^{2}$. The ductus was imaged from the suprasternal and the parasternal short axis windows using colour flow and Doppler.

To estimate intra-observer variability, 14 premature infants with a median gestational age of 29 weeks (range 26-36) and a birthweight of $1340 \mathrm{~g}$ (710-2560) were also studied during high frequency oscillation and conventional mechanical ventilation. All had RDS and were stable at the time of measurements. At 20 minute intervals, 10 infants were measured 13 times during high frequency oscillation and nine infants 12 times during conventional mechanical ventilation. No significant differences between the paired haemodynamic measurements $(S, D$, and LVO) were found either during high frequency oscillation or conventional mechanical ventilation (all $P \geqslant 0.40$ by paired Wilcoxon rank sum test). The coefficients of repeatability ${ }^{9}$ for LVO were $56 \mathrm{ml} / \mathrm{kg} / \mathrm{minute}$ during high frequency oscillation and $60 \mathrm{ml} / \mathrm{kg} /$ minute during conventional mechanical ventilation, and for median LVO $270 \mathrm{ml} / \mathrm{kg} /$ minute and $267 \mathrm{ml} / \mathrm{kg} /$ minute, respectively. They compare favourably with those reported by Fenton et al ${ }^{10}$ in infants whose cardiac output was determined by thermodilution and Doppler technique. For the anterior cerebral artery blood flow velocity, an analysis of variance showed that the SDs (expressed as percentage of mean replicate measurements) caused by intra-observer variability were $1.8 \mathrm{~cm} /$ second $(7 \%)$ for $S$ and $1.1 \mathrm{~cm} /$ second $(18 \%)$ for $\mathrm{D}$, respectively, during high frequency oscillation; during conventional mechanical ventilation, these were $2.1 \mathrm{~cm} /$ second $(8 \%)$ for $S$ and $0.6 \mathrm{~cm} /$ second $(9 \%)$ for $D$, respectively. These levels of reproducibility agree with those reported by Winberg et al. ${ }^{11}$

\section{STATISTICAL ANALYSIS}

Comparisons were made using the paired Wilcoxon rank sum test. A $P$ value of $<0.05$ was considered significant. As we did not know in advance the magnitude of the haemodynamic changes, we recruited eight patients to detect with a power of $80 \%$ at a 0.05 significance level, a variation in CBFV or LVO as large as $1 \mathrm{SD}$ of the mean change. Results are shown as median and range.

\section{Results}

Of the 10 infants recruited, six were studied at both $\mathrm{T} 1$ and $\mathrm{T} 2$, two only at $\mathrm{T} 1$, and two only at T2 leading to eight paired measurements at both study times. Postnatal age at T1 and T2 was 5 hours (3-12) and 40 hours (21-73), respectively. Time interval between measurements during both ventilation modes was 16 minutes $(11-26)$ at $\mathrm{T} 1$ and 12 minutes (10-23) at T2. All patients tolerated surfactant administration and the ventilation mode changes well. No treatment changes were made during the paired measurements. Seven patients had a patent ductus arteriosus with left to right shunt at $\mathrm{T} 1$ and two at $\mathrm{T} 2$.

Table 1 shows the ventilation requirements and the arterial blood gases at $\mathrm{T} 1$ and $\mathrm{T} 2 . \mathrm{FIO}_{2}$ and $\mathrm{AaDO}_{2}$ were significantly higher with conventional mechanical ventilation than with high frequency oscillation at both study times. No significant changes in blood gases occurred between the two ventilation modes. However, at $\mathrm{T} 1, \mathrm{PaCO} 2$ was slightly higher on high 
Table 1 Median (range) ventilation requirements and blood gases during conventional mechanical ventilation and HFOV at $T 1(n=8)$ and $T 2(n=8)$

\begin{tabular}{|c|c|c|c|c|}
\hline & \multicolumn{2}{|l|}{$T 1$} & \multicolumn{2}{|l|}{$T 2$} \\
\hline & $C V$ & $H F O$ & $H F O$ & $C V$ \\
\hline $\begin{array}{l}\text { Mean airway pressure }\left(\mathrm{cm} \mathrm{H}_{2} \mathrm{O}\right) \\
\mathrm{FIO}_{2}(\%) \\
\mathrm{pH} \\
\mathrm{PaCO}_{2}(\mathrm{~mm} \mathrm{Hg}) \\
\mathrm{PaO}_{2}(\mathrm{~mm} \mathrm{Hg}) \\
\mathrm{AaDO}_{2}(\mathrm{~mm} \mathrm{Hg})\end{array}$ & $\begin{array}{l}15(8-19) \\
98(70-100) \\
7 \cdot 34(7 \cdot 22-7 \cdot 38) \\
43(35-60) \\
66(40-112) \\
552(403-626)\end{array}$ & $\begin{array}{l}18(10-21)^{\star \star} \\
88(60-100)^{\star} \\
7 \cdot 32(7 \cdot 24-7 \cdot 37) \\
49(35-55) \\
77(43-83) \\
513(304-621) \Phi\end{array}$ & $\begin{array}{l}13(10-14) \\
40(25-65) \\
7 \cdot 29(7 \cdot 22-7 \cdot 42) \\
43(32-58) \\
71(48-95) \\
172(49-360)\end{array}$ & $\begin{array}{l}10(7-12)^{\star \star} \\
45(35-65)^{\star} \\
7 \cdot 28(7 \cdot 27-7 \cdot 42) \\
45(34-54) \\
78(58-98) \\
194(119-355) \S\end{array}$ \\
\hline
\end{tabular}

${ }^{\star} \mathrm{P}<0.05$ and ${ }^{\star \star} \mathrm{P}<0.01$ (both by study design). $\$ \mathrm{P}<0.05$. CV: conventional ventilation; HFO: high frequency oscillation.

Table 2 Median (range) haemodynamic effects of change from conventional ventilation to HFOV at $T 1(n=8)$ and from $H F O V$ to $C V$ at $T 2(n=8)$

\begin{tabular}{|c|c|c|c|c|}
\hline & \multicolumn{2}{|l|}{$T 1$} & \multicolumn{2}{|l|}{$T 2$} \\
\hline & $C V$ & $H F O$ & $H F O$ & $C V$ \\
\hline $\begin{array}{l}\text { Mean arterial blood pressure }(\mathrm{mm} \mathrm{Hg}) \\
\text { Heart rate } \\
\text { Left ventricular output }(\mathrm{m} / \mathrm{min} / \mathrm{kg}) \\
\text { Maximal cerebral blood flow velocity }(\mathrm{cm} / \mathrm{s}) \\
\text { Minimal cerebral blood flow velocity }(\mathrm{cm} / \mathrm{s}) \\
\text { Resistance index }\end{array}$ & $\begin{aligned} & 43(31-53) \\
& 151(136-162) \\
& 231(139-336) \\
& 29(12-42) \\
& 8(0-14) \\
& 0 \cdot 71(0 \cdot 65-1 \cdot 00)\end{aligned}$ & $\begin{array}{l}41(26-54) \\
149(132-166) \\
200(127-308)^{\star} \\
31(13-38) \\
9(0-12) \\
0 \cdot 73(0 \cdot 60-1 \cdot 00)\end{array}$ & $\begin{array}{l}42(31-57) \\
152(138-170) \\
173(147-259) \\
25(18-51) \\
8(2-16) \\
0.77(0.64-0.91)\end{array}$ & $\begin{array}{l}46(29-53) \\
160(146-168) \\
229(173-286)^{\star} \\
26(19-47) \\
8(0-13) \\
0.72(0 \cdot 64-1 \cdot 00)\end{array}$ \\
\hline
\end{tabular}

$\star \mathrm{P}<0.05$.

frequency oscillation than on conventional mechanical ventilation.

Table 2 shows the haemodynamic effects of ventilation changes at $T 1$ and $T 2$. The only significant haemodynamic changes were a decrease in LVO between conventional mechanical ventilation and high frequency oscillation at $\mathrm{T} 1$, and an increase in LVO between high frequency oscillation and conventional mechanical ventilation at $T 2$ (fig 1) in all patients. At $\mathrm{T} 1$, the decrease in LVO was $33 \mathrm{ml} / \mathrm{min} / \mathrm{kg}(10-73)$. At T2, the increase in LVO was $29 \mathrm{ml} / \mathrm{min} / \mathrm{kg}$ (11-76).

At T1 six out of eight patients showed a decrease in resistance index; one an increase and one no change at $1 \cdot 00$. The changes, however, did not reach significance $(P=0 \cdot 14)$. Using the data presented by Levene et al ${ }^{12}$ and van Bel et al, ${ }^{13}$ we corrected the $\mathrm{RI}$ for $\mathrm{PaCO}_{2}$ variations and their changes approached significance $\left(P=0.09^{12}\right.$ and $P=0 \cdot 06,13$ respectively). At $\mathrm{T} 1$ no significant change in lung inflation was detected radiologically between conventional mechanical ventilation and high frequency oscillation (nine posterior ribs (7-9) with conventional mechanical ventilation and 9 (8-10) with high frequency oscillation; $P=0 \cdot 4)$. At $T 2$ all patients presented a slight degree of lung hyperinflation during high frequency oscillation (nine posterior ribs $(9-10)$ ) before being transferred to conventional mechanical ventilation.

\section{Discussion}

Although the number of subjects is small, our study shows that compared with conventional mechanical ventilation, high frequency oscillation significantly decreased LVO without affecting blood pressure and heart rate in premature infants with RDS. Furthermore, high frequency oscillation significantly improved oxygenation which agrees with previously reported findings. ${ }^{2} 4$
To our knowledge, no study has ever reported on LVO during high frequency oscillation in preterm infants. Animal studies on cardiac output during high frequency oscillation suggest that this does not affect cardiac output as long as lung hyperinflation is avoided. ${ }^{56}$ However, a study in cats showed that an increase in Paw during high frequency oscillation adversely affected cardiac output, but that it was better tolerated when lung compliance was reduced. ${ }^{7}$ A study of cardiac output during high frequency oscillation and conventional mechanical ventilation in one teenager and three toddlers with various very severe lung pathologies, ${ }^{14}$ showed no adverse effect of high frequency oscillation on cardiac output, although the Paw was higher than during conventional mechanical ventilation. However, only a small number of patients with heterogenous pathologies were studied, and their very low lung compliances might have dampened the negative side effect of Paw on cardiac output.

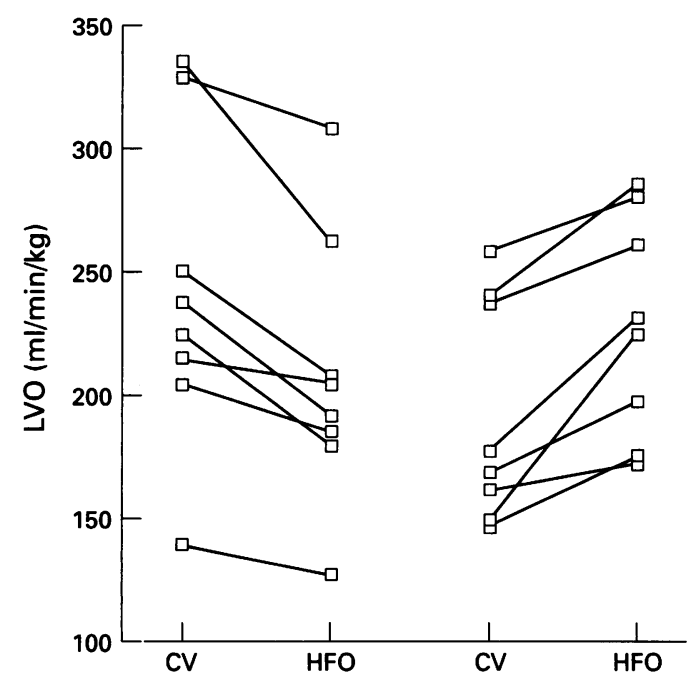

Figure 1 Effects on individual $L V O$ of changes from $C V$ to $H F O$ at $T 1$, and from $H F O$ to $C V$ at $T 2$. 
The mechanisms by which Paw affects cardiovascular function have been well studied. ${ }^{7}{ }^{15}$ An increase in Paw causes various degrees of increase in alveolar volume, depending on the pulmonary compliance. Alveolar expansion can increase pulmonary vascular resistance and therefore diminish venous return. The right ventricular stroke volume is decreased, hence the reduction in cardiac output.

At $\mathrm{T} 1$ and at $\mathrm{T} 2$, all the patients presented a lower LVO with high frequency oscillation than with conventional mechanical ventilation and all the Paw were lower during conventional mechanical ventilation. All our patients had adequate intravascular volumes at the times of measurements as judged by blood pressure, heart rate, and clinical examination. Furthermore, two out of eight patients were receiving dobutamine infusion at $\mathrm{T} 1$ and all eight patients at T2. Dobutamine is a potent inotropic agent in premature infants with RDS. ${ }^{16}$ We therefore postulate that the negative effect on LVO during high frequency oscillation was due to an increase in pulmonary vascular resistance, leading to a decrease in right ventricular stroke volume.

Human adult and animal studies showed that a rise in $\mathrm{PaCO}_{2}$ resulted in a net increase in cardiac output. ${ }^{17} 18 \mathrm{In}$ preterm infants a study suggested that a $1 \mathrm{KPa}$ increase in $\mathrm{PaCO}_{2}$ led to a $10 \%$ decrease in stroke volume. ${ }^{10}$ However, for our group as a whole, the decrease in LVO between conventional mechanical ventilation and high frequency oscillation at $\mathrm{T} 1$ was too important to be related only to the slight $\mathrm{PaCO}_{2}$ increase.

Although we followed a 'high volume' strategy with a potential risk of alveolar overdistention, our patients had similar lung inflation with high frequency oscillation and with conventional mechanical ventilation at $\mathrm{T} 1$. We therefore believe that the drop in LVO with high frequency oscillation at $\mathrm{T} 1$ was not attributable to hyperinflation. At T2, however, all patients presented various degrees of lung hyperinflation with high frequency oscillation and this increased lung volume probably adversely affected LVO.

Animal studies comparing cardiac output and organ blood flow between high frequency oscillation and conventional mechanical ventilation at similar ${ }^{6}$ or different $\mathrm{Paw}^{5}$ did not show any significant change in cerebral blood flow. Only one study evaluated the effects of high frequency oscillation on CBFV in premature infants. ${ }^{19}$ It showed that this was significantly lower in the anterior cerebral artery with high frequency oscillation than with conventional mechanical ventilation. However, the significantly lower $\mathrm{PaCO}_{2}$ during high frequency oscillation might have induced the observed CBFV changes. ${ }^{12} 13$ We could not show any significant change in CBFV with high frequency oscillation compared with conventional mechanical ventilation. As we measured the CBFV over five cardiac cycles only, cycling 20 might have limited the value of our CBFV comparison. However, as both systolic and diastolic velocities seem to vary to the same degree, ${ }^{20}$ cycling variability may not be reflected in the RI. At T1, six of eight patients showed a decrease in $\mathrm{RI}$ with high frequency oscillation. After correcting for $\mathrm{PaCO}_{2}$ changes, the overall variation in RI was close to significance and a type 2 error cannot be excluded. This drop in RI with high frequency oscillation could be the result of a cerebral vasodilatation in response to a falling LVO and a reduced cerebral perfusion pressure, as shown in ventilated newborn piglets. ${ }^{15}$ By analogy we would have expected a similar but opposite change in RI at T2 during transfer from high frequency oscillation to conventional mechanical ventilation. We have no definite explanation for the lack of such change at T2.

In our patients we showed that the LVO during high frequency oscillation was $14 \%$ to $18 \%$ lower than during conventional mechanical ventilation. Systemic vasoconstriction must have occurred at $\mathrm{T} 1$ during high frequency oscillation to maintain blood pressure at the same level as that with conventional mechanical ventilation. This increase in systemic vascular resistance might have decreased blood flow to organs other than the brain as shown by Mirro et al ${ }^{15}$ in piglets during conventional mechanical ventilation at variable Paw. At T2, the rise in LVO during transfer from high frequency oscillation to conventional mechanical ventilation might have led to an increase in organ blood flow. Changes in organ blood flow are critical in premature infants. They were related to periventricular haemorrhage ${ }^{20}$ or necrotising enterocolitis. The correlations between high frequency oscillation, LVO, $\mathrm{CBFV}$ and organ blood flow merit further evaluation.

1 Clark RH, Gerstmann DR, Null DM, deLemos RA Prospective randomized comparison of high-frequency oscillatory and conventional ventilation in respiratory distress syndrome. Pediatrics 1992; 89: 5-12.

2 Ogawa Y, Miyasaka K, Kawano T, Imura S, Inukai $\mathrm{K}$ Okuyama $\mathrm{K}$, et al. A multicenter randomized trial of high frequency oscillatory ventilation as compared with conventional mechanical ventilation in preterm infants with respiratory failure. Early Hum Dev 1993; 32: with 10 .

3 The HIFI Study Group. High-frequency oscillatory ventilation compared with conventional mechanical ventilation in the treatment of respiratory failure in preterm infants. $N$ Engl f Med 1989; 320: 88-93.

4 HIFO Study Group. Randomized study of high-frequency oscillatory ventilation in infants with severe respiratory distress syndrome. $\mathcal{F}$ Pediatr 1993; 122: 609-19.

5 Kinsella JP, Gerstmann DR, Clark RH, Null DM, Morrow WR, Taylor AF, et al. High-frequency oscillatory ventilation versus intermittent mandatory ventilation: early hemodynamic effects in the premature baboon with hyaline membrane disease. Pediatr Res 1991; 29: $160-6$.

6 Mirro R, Tamura M, Kawano T. Systemic cardiac output and distribution during high-frequency oscillation. Crit Care Med 1985; 13: 724-32.

7 Traverse JH, Korvenranta H, Adams EM, Goldthwait DA, Carlo WA. Cardiovascular effects of high-frequency oscilCarlo WA. Cardiovascular effects of high-frequency
latory and jet ventilation. Chest 1989; 96: 1400-4.

8 Gardin JM, Tobis JM, Dabestani A, Smith C, Elkayam U Castelman E, et al. Superiority of two-dimensional measurement of aortic vessel diameter in Doppler echocardiographic estimates of left ventricular stroke volume. F Am Coll Cardiol 1985; 6: 66-74.

9 Bland JM, Altman DG. Statistical methods for assessing agreement between two methods of clinical measurement. Lancet 1986; i: 307-10.

10 Fenton AC, Woods KL, Leanage R, Abu-Harb M, Levene MI, Evans DH, et al. Cardiovascular effects of carbon dioxide in ventilated preterm infants. Acta Paediatr 1992; 81: 498-503.

11 Winberg P, Dahlström A, Lundell B. Reproducibility of intracranial Doppler flow velocimetry. Acta Paediatr Scand 1986; 329 (suppl): 134-9.

12 Levene MI, Shortland D, Gibson N, Evans DH. Carbon dioxide reactivity of the cerebral circulation in extremely premature infants: effects of postnatal age and indomethacin. Ped Res 1988; 24: 175-9. 
13 Van Bel F, van de Bor M, Baan J, Ruys JH. The influence of abnormal blood gases on cerebral blood flow velocity in abnormal blood gases on cerebral blood flow velocity in

14 Arnold JH, Truog RD, Thompson JE, Fackler JC. High-frequency ventilation in pediatric respiratory failure. Crit Care Med 1993; 21: 272-8.

15 Mirro R, Busija D, Green R, Leffler C. Relationship between mean airway pressure, cardiac output, and organ blood flow with normal and decreased respiratory compliance. $\mathcal{F}$ Pediatr 1987; 111: 101-6.

16 Rozé JC, Tohier C, Maingueneau C, Lefèvre M, Mouzard A. Response to dobutamine and dopamine in the hypotensive very preterm infant. Arch Dis Child 1993; 69: 59-63.
17 Norman J, Atkinson SA. The effect of cardiac sympathetic blockade on the relationship between cardiac output and carbon dioxide tension in anaesthetized dog. $B r \mathcal{F}$ Anaesth carbon dioxide tension in anaesthetized dog. Brf Anaesth

18 Cullen DJ, Eger EI. Cardiovascular effects of carbon dioxide in man. Anesthesiology 1974; 41: 345-9.

9 Schlosser RL, Rettwitz-Volk W, Allendorf A, von Loewenich V. Haemodynamische Auswirkungen des hochfrequenten Oscillationsbeatmung bei Frueh- und reifen Neugeborenen. Klin Paediatr 1994; 206: 421-4.

20 Anthony MY, Evans DH, Levene MI. Cyclical variations in cerebral blood flow velocity. Arch Dis Child 1991; 66: $12-16$ 